\title{
Perception and prevalence of behavioral risk factors: the lifestyle risk scale (LRS)
}

\author{
Beatrix Algurén ${ }^{1,2 \#}$, Rolf Weitkunat ${ }^{3,4}$ \\ ${ }^{1}$ School of Health Sciences, Jönköping University, Jönköping, Sweden; \\ ${ }^{2}$ Institute for Health and Rehabilitation Sciences (IHRS), Ludwig-Maximilians-University, Munich, Germany; \\ ${ }^{\#}$ Corresponding Author: beatrix.alguren@hhj.hj.se \\ ${ }^{3}$ Institute for Medical Informatics, Biometry and Epidemiology, University of Munich, Munich, Germany (during the study period); \\ ${ }^{4}$ R\&D Fellow, Philip Morris Products SA, Neuchâtel, Switzerland (current affiliation).
}

Received 29 August 2011; revised 23 September 2011; accepted 21 October 2011.

\begin{abstract}
Objective: To develop a lifestyle risk scale (LRS) of health-related behaviors based on risk assessments of study participants. Method: By means of pairwise comparisons of assessed risks associated with tobacco, alcohol, obesity, fast-food, physical inactivity, and lack of sleep, each at four levels, 24 behaviors were ranked on a unidimensional risk scale. Results: Overall, use of tobacco was assigned the highest risk score (3.7), consumption of fast-food and lack of sleep the lowest $(1.7,1.6)$. Minor risk factors (lack of sleep and fast-food) were, at their highest levels, assigned similar risk values as major risk factors (tobacco, alcohol, obesity) at their lowest levels. Lifestyles of female participants were less hazardous than those of male participants, as measured with the LRS. In contrast, perception of behavioral health risks was more precise in men. Conclusions: The LRS provides a practical quantification to identify and compare groups with different risk behavior patterns as well as clusters of risky health behaviors in and across populations. It can also support the communication of behavioral health risks.
\end{abstract}

Keywords: Health Behavior; Lifestyle Score; Risk Communication; Risk Perception

\section{INTRODUCTION}

It is generally accepted that in Western populations chronic diseases are largely due to unhealthy lifestyles $[1,2]$. In addition, health-related behaviors affect a va-

*The opinions and conclusions of the researchers are their own and do not necessarily reflect Philip Morris International, Inc.'s position. riety of acute illness conditions [3]. The need for monitoring and promoting healthy lifestyles arises as being probably the major public health challenge to decrease the burden of non-communicable diseases [2-4]. One of the problems related to lifestyle-prevention is the causal and structural complexity of lifestyles. A more general problem in health-education is that epidemiologic risk measures are not easily understood by most addressees $[5,6]$. To address unhealthy lifestyles effectively, it appears that four aspects need to be considered: 1) an association of the target risk behaviors with negative health outcomes must have been verified, 2) risk groups and clusters of risk factors have to have been identified, 3) successful procedures must be developed to address the target groups effectively, and 4) effectiveness of interventions must be rigorously evaluated. Step one has been achieved generally for several risk factors [7-16]. To succeed with step two, several scores have been developed [17-20], the chronic disease risk index (CDRI) [17] and the Lifestyle Index (LI) [18] are two examples. Diet, physical activity, smoking, and alcohol consumption are considered in both instruments. The CDRI additionally includes the body mass index (BMI). In these studies, behavioral risk factors were assigned scores relative to their epidemiological risks. The CDRI scoring system helped to identify different populations at different levels of risk in a multiethnic cohort [17]. In a cross national comparison between China and the United States similarities of lifestyle patterns but also different unhealthy behaviors were identified with the Lifestyle Index [18]. Both indices seem to solve the problem of identifying and comparing high risk groups. On the other hand, neither directly allows for comparing risks across different behaviors and behavior patterns. Consequently, neither supports evaluating interventions with multidimensional behavioral effects, since so far it is not possible to assess changes in health risks associated with 
complex changes in health risk behavior patterns. It would therefore be desirable to have a unidimensional risk scale available for combinations of health-related behaviors, which could also support communicating lifestyle risks in an easily understandable way [6].

The lack of such an instrument was the motivation to develop a unidimensional risk scale for ranking behavioral risks according to their health impact. In the absence of comprehensive epidemiological data on the health impacts of multiple behavioral risk factors, that would allow a direct analysis of risks, the underlying quantification can only be based on subjective knowledge represented in a sample of individuals. In the present study, based on pair-wise comparisons, six behaveioral risks were ranked on a lifestyle risk scale, reflecting subjective risk perceptions using a multidimensional scaling method [21]. The development of the Lifestyle Risk Scale (LRS) is descrybed, as well as the risks of the study population, based on applying the scale to the reported actual behaviors.

\section{METHODS}

\subsection{Design}

This cross-sectional survey sampled primarily health experts from public health schools in Germany and staff from the Munich university hospital. No random sample could be drawn since a population-representative list of potential participants with information on professions was not available. Initially, 713 questionnaires were emailed with the request to reply anonymously and to possibly forward the questionnaire on to others. Recruitment of the targeted convenience sample was ongoing from May to August 2004. The sample size was determined by the available number of addresses of health experts.

\subsection{Measurements}

The self-administered questionnaire covered three areas: sociodemographic and anthropometric variables (sex, age, weight, height, citizenship, professional training, current occupation, partnership, children), individual health related behaviors (smoking, alcohol consumption, physical activity, fast food consumption, duration of sleep) using four ordinal response categories, and the appraisal of 24 pairs of lifestyle risk factors. The latter were defined considering the guidelines for reducing chronic diseases [2], and study participants were asked about their risk assessment regarding tobacco and alcohol consumption, obesity, daily physical activity, weekly fast food consumption and sleeping hours, each dimension divided into four increasing degrees of risk. The 24 intensities (or levels of manifestation) of the six con- sidered behavior related risk dimensions are shown in Table 3 Each of the 24 manifestations was to be compared with each other by participants indicating in each pairwise comparison which specific health-related behavior they considered more dangerous. The instruction was to imagine an 18-year-old man, sticking to either behavior to be assessed for the rest of his life. Due to the large number of 240 not permuted pairs of risk behavior manifestation comparisons (276 possible minus six trivial intra-dimension comparisons for each of the six behavior-related risk dimensions), ten different questionnaires were used, each containing a randomly selected fixed set of 24 comparisons. Prior to the main study the questionnaires were answered by 39 public health students and no difficulties were reported during this pretest.

\subsection{Statistical Analyses}

All measured and derived sociodemographic, anthropometric, and health behavior variables were described according to their measurement scale by absolute and relative frequencies or by mean \pm standard deviation as well as median and 25 th and 75 th percentiles. The BMI (weight $(\mathrm{kg}) /$ height $(\mathrm{m} 2)$ ) was derived and BMI under 18.5 indicated underweight, BMI between 18.5 and 25 normal weight, BMI between 25 and 30 overweight, and BMI above 30 obesity (WHO 1998). LRS item scores were estimated using the Bradley-TerryLuce (BTL) model for paired comparisons of ranked stimuli [22]. The model is based on the assumption that the probability of choosing an alternative is proportional to the "utility" of this alternative in terms of its health risk impact [23]. It is assumed that the utility of a specific item is linked to the response probability by a logistic function. The regression parameters were derived from fitting logistic models without offset to the data obtained in the study. By subtracting the smallest regression parameter from each of the 24 regression parameters [21], a rational scale with a minimum value of zero was obtained. The lifestyle risk scale was derived using the SAS program provided in [24]. In addition to analyzing the total sample, separate models were fitted to the data obtained from health professionals and laymen.

For every participant, an individual risk score corresponding to his or her actual lifestyle was calculated by using the parameter estimates derived with the BTL scoring of the total sample data. In addition, individual risk perception scores based on individual appraisals of life-styles were determined for each participant. This was done accounting for the fact that the 240 comparisons were distributed to ten versions of the questionnaire. In the first step, each risk specification as assessed by each participant was quantified using the final LRS 
parameters. Then the sum of the 24 values of each participant was subtracted from the maximal value which was possible with the specific version of the questionnaire. Finally, to warrant comparability across the ten versions of the questionnaire, the score was divided by the range of risk appraisals possible with the specific questionnaire version. For convenience, the score was finally multiplied by 100 . Higher values represent larger deviations of the group estimates, i.e. poorer risk perception in terms of underestimation of risk.

The assumption of homogeneity of the assessments of the study participants regarding their comparisons of pairs of risk behaviors was analyzed by an adaptation of Cochran's Q-test [23], based on calculating the ratio of inter-item and inter-individual variability. To assess the split-half reliability of the scale, Cronbach's alpha (coefficient of reliability) was calculated [25], considering a value of 0.9 or above as being indicative of high reliability [26]. U-tests were performed to investigate differences in sex and partnership status as well as differences between subgroups of age, professional training, and current occupation with respect to risk scores and risk perception scores. Spearman rank correlation coefficients $\left(r_{\mathrm{sp}}\right)$ were used to correlate risk scores with age as well as with risk perception scores. All tests were performed two-sided at local alpha levels of 5 percent without adjustment for multiplicity. All statistical analyses were carried out with SAS (Statistical Analysis System, Version 8.2).

\section{RESULTS}

\subsection{Demographic and Lifestyle Characteristics}

As expected, the number of returned questionnaires was different for each of the ten versions. To obtain an equal distribution, 32 returned questionnaires of each of the ten versions were randomly retained. Therefore, only 320 of the 434 returned questionnaires (64 questionnaires were undeliverable because of wrong emailaddresses) were used for further analyses, 43 percent of which were from health professionals.

The analyses included 202 women with an average age of $33.3 \pm 8.2$ years and an average BMI of $21.6 \pm$ $2.2 \mathrm{~kg} / \mathrm{m}^{2}$. The 116 men were $33.2 \pm 9.0$ years old and had an average BMI of $24.2 \pm 2.8 \mathrm{~kg} / \mathrm{m}^{2}$. Two participants did not report their sex. Most participants lived in Germany (77\%) and did not lead risky lifestyles: 85 percent were non-smokers, 83 percent had normal weight, 71 percent drank less than one drink per day and 69 percent ate fast food less than once a week. Sample characteristics and lifestyle variables are described in Table 1 and Table 2, respectively.

\subsection{Assessment of Risk Behaviors}

The assessments of risk behaviors were homogeneous in the sample $(p<0.001)$. Table 3 contains the LRS scores based on the pairwise assessments of the 24 risk behavior manifestations. The reported results refer to models based on the total sample data set, as well as on data obtained from laymen and from health professionals.

The values range from 0 ('sleep less than six hours once a week') to 4.8 ('four drinks per day'). On average, smoking was perceived as the most risky behavior (3.7), followed by alcohol consumption (3.1) and obesity (3.0). Lack of sleep and fast-food consumption were assessed as being less risky (1.7 and 1.6). The assessed health risk of physical inactivity was 57 percent of that of smoking (2.1 vs. 3.7). Less major risks such as lack of sleep and fast-food consumption were at higher levels of manifestation assigned similar risk scores as the major risks of smoking, alcohol and obesity at lower levels. For instance, "fast-food four times per week" scored 2.8, a similar value to that obtained for "two drinks per day" (2.7) or "five cigarettes per day" (2.6). "Daily sleep under six hours four times per week" scored as even riskier (3.2). Figure 1 contains the unidimensional LRS scores based on the total sample analysis.

As can be seen, in order to apply the scale, only information related to the considered health-behaviors is required at sufficient granularity, whereas there is no need for using a particular questionnaire. This has the advantage that data collected with different instruments can be analyzed using the LRS scoring, given the required information is available. An individual lifestyle risk index can be determined by adding up the values corresponding to an individual's health-behaviors and levels of manifestation.

To evaluate the reliability of the scores, the two scales were compared which were derived separately for the assessments made by health professionals (participants with professional medical or public health background, $\mathrm{N}=136$ ) and laymen (participants with neither professional medical, public health, sociological/pedagogical, psychological, biological, nor pharmacological background, $N=129$ ). To warrant some homogeneity of the two assessment populations, participants which did not fall in one of these two subgroups were not considered in the reliability analysis. The two scales were found to correlate strongly (Cronbach's Alpha $=0.98, \mathrm{p}<0.0001$ ). For almost all specific risk behaviors, scores were higher in the assessments of health professionals than in those of laymen. Overall, the highest scores were obtained for tobacco, the lowest for fast food consumption. 
Table 1. Characteristics of the sample.

\begin{tabular}{|c|c|c|c|c|c|c|}
\hline \multirow[b]{2}{*}{ Variable } & \multicolumn{2}{|c|}{ Women $(\mathrm{N}=202)$} & \multicolumn{2}{|c|}{$\operatorname{Men}(\mathrm{N}=116)$} & \multicolumn{2}{|c|}{ Total $(\mathrm{N}=320)$} \\
\hline & No. & $\%$ & No. & $\%$ & No. & $\%$ \\
\hline \multicolumn{7}{|l|}{ Age [years] } \\
\hline $20-29$ & 59 & 29.2 & 45 & 38.8 & 104 & 32.5 \\
\hline $30-39$ & 67 & 33.2 & 29 & 25.0 & 96 & 30.0 \\
\hline $40-49$ & 22 & 10.9 & 14 & 12.1 & 36 & 11.3 \\
\hline $50-59$ & 7 & 3.5 & 3 & 2.6 & 10 & 3.1 \\
\hline $60+$ & 1 & 0.5 & 2 & 1.7 & 3 & 0.9 \\
\hline no answer & 46 & 22.8 & 23 & 19.8 & 71 & 22.2 \\
\hline \multicolumn{7}{|l|}{ Weight } \\
\hline underweight & 9 & 4.5 & 1 & 0.9 & 10 & 3.1 \\
\hline normal weight & 175 & 86.6 & 76 & 65.5 & 253 & 79.1 \\
\hline overweight & 17 & 8.4 & 33 & 28.5 & 50 & 15.6 \\
\hline adiposity & 0 & 0 & 6 & 5.2 & 6 & 1.9 \\
\hline no answer & 1 & 0.5 & 0 & 0 & 1 & 0.3 \\
\hline \multicolumn{7}{|l|}{ Partnership } \\
\hline alone & 67 & 33.2 & 38 & 32.8 & 107 & 33.4 \\
\hline with partner & 135 & 66.8 & 78 & 67.3 & 213 & 66.6 \\
\hline \multicolumn{7}{|l|}{ Children } \\
\hline yes & 49 & 24.3 & 30 & 25.9 & 79 & 24.7 \\
\hline no & 153 & 75.7 & 85 & 73.3 & 240 & 75.0 \\
\hline no answer & 0 & 0 & 1 & 0.9 & 1 & 0.3 \\
\hline \multicolumn{7}{|l|}{ Citizenship } \\
\hline Germany & 157 & 77.7 & 89 & 76.7 & 247 & 77.2 \\
\hline Switzerland & 29 & 14.4 & 22 & 19.0 & 52 & 16.3 \\
\hline Austria & 5 & 2.5 & 2 & 1.7 & 7 & 2.2 \\
\hline other & 11 & 5.5 & 3 & 2.6 & 14 & 4.4 \\
\hline \multicolumn{7}{|l|}{ Professional training } \\
\hline Medicine & 23 & 11.4 & 15 & 13.0 & 38 & 11.9 \\
\hline Public health & 76 & 37.6 & 20 & 17.2 & 98 & 30.6 \\
\hline Sociology/Pedagogy & 13 & 6.4 & 6 & 5.2 & 19 & 5.9 \\
\hline Psychology & 14 & 6.9 & 4 & 3.5 & 18 & 5.6 \\
\hline Biology & 8 & 4.0 & 1 & 0.9 & 9 & 2.8 \\
\hline Pharmacy & 3 & 1.5 & 2 & 1.7 & 5 & 1.6 \\
\hline other & 63 & 31.2 & 66 & 56.9 & 129 & 40.3 \\
\hline no answer & 2 & 1.0 & 2 & 1.7 & 4 & 1.3 \\
\hline \multicolumn{7}{|l|}{ Current occupation } \\
\hline self-employed & 16 & 7.9 & 18 & 15.5 & 34 & 10.6 \\
\hline company-employed & 123 & 60.9 & 67 & 57.8 & 191 & 59.7 \\
\hline civil servant & 5 & 2.5 & 4 & 3.5 & 9 & 2.8 \\
\hline unemployed & 5 & 2.5 & 3 & 2.6 & 9 & 2.8 \\
\hline student & 46 & 22.8 & 19 & 16.4 & 65 & 20.3 \\
\hline other & 6 & 3.0 & 5 & 4.3 & 11 & 3.4 \\
\hline no answer & 1 & 0.5 & 0 & 0 & 1 & 0.3 \\
\hline
\end{tabular}

\subsection{Lifestyle Risk Scores and Risk Perception Scores in the Study Population}

The risk scores according to actual health-related behaviors of the study participants are shown in Table 4, stratified by sex, age, professional training, occupation and partnership.

The observed risk scores in the sample ranged from 0 to 12.5 , the median being 2.2. Men scored higher (2.9) than women $(1.5, \mathrm{p}<0.001)$, singles higher (2.6) than non-singles $(1.5, \mathrm{p}<0.013)$, self-employed participants higher (2.5) than students $(1.5, \mathrm{p}<0.083)$, and participants with a medical background scored higher (2.7) than participants without a health-professional background $(2.0, \mathrm{p}<0.078)$.

Table 5 contains the risk perception scores, stratified by sex, age, professional training, occupation, partnership, and by their risk behaviors. Higher values denote more pronounced underestimation of the health risks relative to the assessment of the total sample. The scores ranged from 0 to 29.4 , the median was 4.0 . The risk perception score correlated slightly negatively with age $(\mathrm{rsp}=-0.15, \mathrm{p}<0.05)$. Risk perception in men (3.7) was more accurate than in women $(4.1, \mathrm{p}<0.91)$, more accurate in participants with medical background (3.2) than in those with no health professional background (4.2, $\mathrm{p}<0.071)$, and more accurate in students (4.4) than 


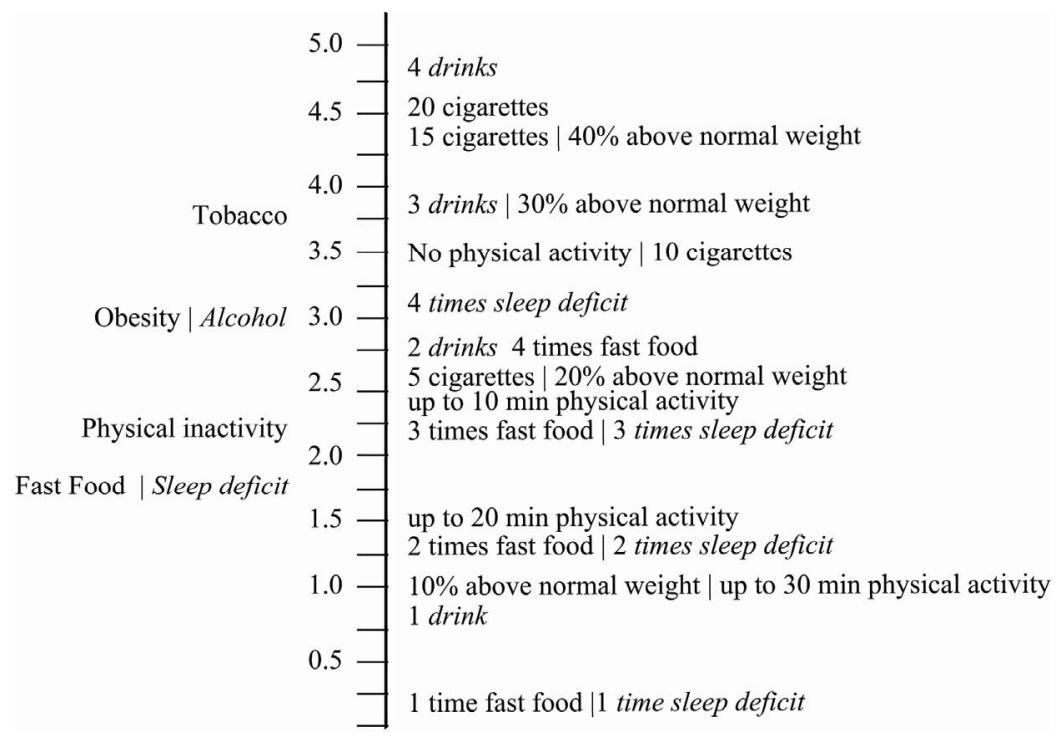

Figure 1. The lifestyle risk scale (LRS) derived from the health risk assessments of the study participants. Measures of tobacco, alcohol, physical inactivity: daily; measures of fast food, sleep deficit: weekly.

Table 2. Actual lifestyles of the sample.

\begin{tabular}{|c|c|c|c|c|c|c|}
\hline & \multicolumn{2}{|c|}{ Women $(\mathrm{N}=202)$} & \multicolumn{2}{|c|}{$\operatorname{Men}(\mathrm{N}=116)$} & \multicolumn{2}{|c|}{ Total $(\mathrm{N}=320)$} \\
\hline & No. & $\%$ & No. & $\%$ & No. & $\%$ \\
\hline \multicolumn{7}{|l|}{ Obesity } \\
\hline no & 185 & 91.6 & 77 & 66.4 & 264 & 82.5 \\
\hline $10 \%$ & 15 & 7.4 & 27 & 23.3 & 42 & 13.1 \\
\hline $20 \%$ & 2 & 1.0 & 6 & 5.2 & 8 & 2.5 \\
\hline $30 \%$ & 0 & 0 & 5 & 4.3 & 5 & 1.6 \\
\hline $40 \%$ & 0 & 0 & 1 & 0.9 & 1 & 0.3 \\
\hline \multicolumn{7}{|l|}{ Fast Food per week } \\
\hline$<1$ & 148 & 73.3 & 72 & 62.1 & 221 & 69.1 \\
\hline up to once & 41 & 20.3 & 29 & 25.0 & 70 & 21.9 \\
\hline up to twice & 9 & 4.5 & 5 & 4.3 & 14 & 4.4 \\
\hline up to three times & 4 & 2.0 & 4 & 3.5 & 8 & 2.5 \\
\hline$>$ three times & 0 & 0 & 6 & 5.2 & 7 & 2.2 \\
\hline \multicolumn{7}{|l|}{ Cigarettes per day } \\
\hline non-smoker & 179 & 88.6 & 91 & 78.5 & 271 & 84.7 \\
\hline up to 5 & 10 & 5.0 & 13 & 11.2 & 23 & 7.2 \\
\hline up to 10 & 2 & 1.0 & 4 & 3.5 & 6 & 1.9 \\
\hline up to 15 & 4 & 2.0 & 7 & 6.0 & 11 & 3.4 \\
\hline$>15$ & 7 & 3.5 & 1 & 0.9 & 9 & 2.8 \\
\hline \multicolumn{7}{|l|}{ Alcohol per day } \\
\hline$<1$ drink & 159 & 78.7 & 65 & 56.0 & 226 & 70.6 \\
\hline up to 1 drink & 38 & 18.8 & 29 & 25.0 & 67 & 20.9 \\
\hline up to 2 drinks & 5 & 2.5 & 19 & 16.4 & 24 & 7.5 \\
\hline up to 3 drinks & 0 & 0 & 3 & 2.6 & 3 & 0.9 \\
\hline$>3$ drinks & 0 & 0 & 0 & 0 & 0 & 0 \\
\hline \multicolumn{7}{|l|}{ Physical activity per day } \\
\hline$>30$ minutes & 99 & 49.0 & 51 & 44.0 & 151 & 47.2 \\
\hline up to 30 minutes & 38 & 18.8 & 27 & 23.3 & 65 & 20.3 \\
\hline up to 20 minutes & 44 & 21.8 & 26 & 22.4 & 71 & 22.2 \\
\hline up to 10 minutes & 18 & 8.9 & 12 & 10.0 & 30 & 9.4 \\
\hline no physical activity & 3 & 1.5 & 0 & 0 & 3 & 0.9 \\
\hline \multicolumn{7}{|c|}{ Days with sleep under 6 her week } \\
\hline$<1$ & 92 & 45.5 & 52 & 44.8 & 145 & 45.3 \\
\hline up to 1 & 54 & 26.7 & 32 & 27.6 & 87 & 27.2 \\
\hline up to 2 & 31 & 15.4 & 20 & 17.3 & 51 & 15.9 \\
\hline up to 3 & 6 & 3.0 & 9 & 7.8 & 15 & 4.7 \\
\hline$>3$ & 19 & 9.4 & 3 & 2.6 & 22 & 6.9 \\
\hline
\end{tabular}


Table 3. LRS scores derived by the BTL-model in the total sample, in health experts, and in laymen (separate models).

\begin{tabular}{|c|c|c|c|c|c|c|}
\hline \multirow[b]{2}{*}{ Risk factor } & \multicolumn{2}{|c|}{$\begin{array}{l}\text { Health professionals } \\
\qquad(\mathrm{N}=136)\end{array}$} & \multicolumn{2}{|c|}{$\begin{array}{c}\text { Laymen } \\
(\mathrm{N}=129)\end{array}$} & \multicolumn{2}{|c|}{$\begin{array}{c}\text { Total } \\
(\mathrm{N}=320)\end{array}$} \\
\hline & $\beta$ & Score & $\beta$ & Score & $\beta$ & Score \\
\hline Obesity & & Mean 4.2 & & Mean 3.6 & & Mean 3.0 \\
\hline $10 \%$ above normal weight & -2.9257 & 1.4 & -2.5611 & 1.5 & -2.1593 & 1.0 \\
\hline $20 \%$ above normal weight & -0.2255 & 4.1 & -1.1138 & 3.0 & -0.5908 & 2.6 \\
\hline $30 \%$ above normal weight & 0.9285 & 5.3 & 0.7983 & 4.9 & 0.71 & 3.9 \\
\hline $40 \%$ above normal weight & 1.7184 & 6.1 & 1.1689 & 5.2 & 1.2238 & 4.4 \\
\hline $\begin{array}{l}\text { Fast Food (e.g., hamburger, hot dogs, } \\
\text { pizzas, french fries, currywurst) }\end{array}$ & & Mean 2.3 & & Mean 2.1 & & Mean 1.6 \\
\hline Once a week & -4.3664 & 0 & -3.6121 & 0.5 & -3.1223 & 0.1 \\
\hline Twice a week & -2.3563 & 2.0 & -2.3964 & 1.7 & -1.9093 & 1.3 \\
\hline Three times a week & -1.1345 & 3.2 & -1.3054 & 2.8 & -0.9146 & 2.3 \\
\hline Four times a week & -0.2205 & 4.1 & -0.6798 & 3.4 & -0.4349 & 2.8 \\
\hline Tobacco & & Mean 5.3 & & Mean 4.5 & & Mean 3.7 \\
\hline Up to 5 cigarettes a day & -0.6156 & 3.8 & -0.8145 & 3.3 & -0.6357 & 2.6 \\
\hline Up to 10 cigarettes a day & 0.6778 & 5.0 & -0.0106 & 4.1 & 0.308 & 3.5 \\
\hline Up to 15 cigarettes a day & 1.571 & 5.9 & 1.3056 & 5.4 & 1.2042 & 4.4 \\
\hline Up to 20 cigarettes a day & 2.0311 & 6.4 & 1.0855 & 5.2 & 1.3025 & 4.5 \\
\hline $\begin{array}{l}\text { Alcohol (Definition "drink": } 0.251 \\
\text { wine or } 0.51 \text { beer or one little glass of }\end{array}$ & & Mean 4.4 & & Mean 3.6 & & Mean 3.1 \\
\hline 1 drink a day & -3.2276 & 1.1 & -2.8617 & 1.2 & -2.3394 & 0.9 \\
\hline 2 drinks a day & -0.594 & 3.8 & -0.8962 & 3.2 & -0.4649 & 2.7 \\
\hline 3 drinks a day & 1.3141 & 5.7 & 0.4244 & 4.5 & 0.7275 & 3.9 \\
\hline 4 drinks a day & 2.4534 & 6.8 & 1.4899 & 5.6 & 1.6203 & 4.8 \\
\hline Physical inactivity & & Mean 3.2 & & Mean 2.4 & & Mean 2.1 \\
\hline Maximal $30 \mathrm{~min}$ a day & -2.8638 & 1.5 & -3.0063 & 1.1 & -2.1958 & 1.0 \\
\hline Maximal 20 min a day & -1.6235 & 2.7 & -2.4243 & 1.7 & -1.748 & 1.5 \\
\hline Maximal 10 min a day & -0.8944 & 3.5 & -1.1975 & 2.9 & -0.8167 & 2.4 \\
\hline None a day & 0.7417 & 5.1 & -0.0837 & 4.0 & 0.3006 & 3.5 \\
\hline $\begin{array}{l}\text { Lack of sleep ("Sleeping less than six } \\
\text { hours a day") }\end{array}$ & & Mean 2.4 & & Mean 2.2 & & Mean 1.7 \\
\hline Once a week & -4.0309 & 0.3 & -4.0741 & 0 & -3.2046 & 0 \\
\hline Twice a week & -2.8267 & 1.5 & -2.4233 & 1.7 & -1.9859 & 1.2 \\
\hline Three times a week & -0.944 & 3.4 & -1.1113 & 3.0 & -0.8788 & 2.3 \\
\hline Four times a week & 0 & 4.4 & 0 & 4. 1 & 0 & 3.2 \\
\hline
\end{tabular}

in self-employed participants $(5.2, \mathrm{p}<0.078)$. When the distribution of the risk perception score was examined across body weight strata as well as across tobacco and alcohol consumption patterns, no substantial associations were apparent. There was virtually no correlation between actual behavior-based scores on the one hand and risk perception scores on the other ( $r s p=0.02, p<0.72)$.

\section{DISCUSSION}

A lifestyle risk scale (LRS) was developed, based on pairwise comparisons of health-risks of specific healthrelated behaviors, using the BTL model. Lifestyles were treated as objects with specific manifestations of risk behaviors as their attributes. For a realistic evaluation of the attributes, the measures had to be easy to comprehend and overloading study participants with too many pairwise comparisons [22] had to be avoided. Consequently, the 240 pairwise comparisons were randomly distributed to ten questionnaires, each comprising 24 pairwise comparisons. Six health-related behavior in- dicators, each of which had four ordinal levels of manifestation, were to be assessed. In addition to LRS scores, risk scores corresponding to actual individual behaviors as well as to individual LRS risk perception scores were determined for each participant.

Among the six risk categories to be assessed, paramount importance was assigned to smoking as well as to obesity. This is in agreement with epidemiological findings [2,27-30]. The LRS scores thus appear to allow for a fine-grained unidimensional ranking of perceived as well as of actual risk, not only of dimensions of risk behaviors, but also of specific intensity levels at which these behaviors are performed. The finding, for example, that 'one drink per day' was perceived as less risky than 'physical activity not longer than 30 minutes a day' seems to reflect the available evidence on health benefits of moderate red wine consumption [4,31-33] and also the recommendation of daily moderate physical activity with a minimum of 30 minutes [2]. The findings of the study further indicate that with regard to subjective risk percep- 
Table 4. Lifestyle risk scores of the sample based on applying the LRS on actual behaviors.

\begin{tabular}{|c|c|c|c|c|c|c|c|c|c|c|c|c|}
\hline \multirow[b]{2}{*}{ Variables } & \multicolumn{4}{|c|}{ Women $(\mathrm{N}=202)$} & \multicolumn{4}{|c|}{ Men $(\mathrm{N}=116)$} & \multicolumn{4}{|c|}{ Total $(\mathrm{N}=320)$} \\
\hline & $\begin{array}{c}25 \text { th } \\
\text { percentile }\end{array}$ & Median & $\begin{array}{c}75 \text { th } \\
\text { percentile }\end{array}$ & Mean & $\begin{array}{c}25 \text { th } \\
\text { percentile }\end{array}$ & Median & $\begin{array}{c}75 \text { th } \\
\text { percentile }\end{array}$ & Mean & $\begin{array}{c}25 \text { th } \\
\text { percentile }\end{array}$ & Median & $\begin{array}{c}\text { 75th } \\
\text { percentile }\end{array}$ & Mean \\
\hline total & 1.0 & 1.5 & 3.3 & 2.2 & 1.1 & 2.9 & 5.1 & 3.7 & 1.0 & 2.2 & 4.0 & 2.7 \\
\hline \multicolumn{13}{|l|}{ Age years } \\
\hline $20-29$ & 0.9 & 1.5 & 3.2 & 2.1 & 1.2 & 2.9 & 5.0 & 3.4 & 0.9 & 2.1 & 4.2 & 2.7 \\
\hline $30-39$ & 0.1 & 1.2 & 3.2 & 2.2 & 0.9 & 2.4 & 4.7 & 3.3 & 0.9 & 1.5 & 3.5 & 2.5 \\
\hline $40-49$ & 1.2 & 1.4 & 2.7 & 2.1 & 1.0 & 2.2 & 5.5 & 3.3 & 1.5 & 1.7 & 3.6 & 2.6 \\
\hline $50-59$ & 1.1 & 3.7 & 4.8 & 3.7 & 0 & 3.4 & 6.8 & 3.4 & 1.5 & 3.5 & 4.8 & 3.6 \\
\hline $60+$ & 2.6 & 2.6 & 2.6 & 2.6 & 0 & 1.4 & 2.8 & 1.4 & 0 & 2.6 & 2.8 & 1.8 \\
\hline no answer & 1.0 & 1.7 & 3.3 & 2.1 & 2.1 & 4.3 & 7.3 & 5.0 & 1.0 & 2.4 & 4.1 & 3.1 \\
\hline \multicolumn{13}{|l|}{ Professional training } \\
\hline Medicine & 0.1 & 2.4 & 4.3 & 2.9 & 2.5 & 3.4 & 5.1 & 4.0 & 1.5 & 2.7 & 4.7 & 3.3 \\
\hline Psychology & 1.0 & 1.7 & 3.5 & 2.3 & 0.6 & 2.4 & 5.0 & 2.8 & 1.0 & 1.5 & 3.7 & 2.3 \\
\hline Sociology/Pedagogy & 1.0 & 1.3 & 1.5 & 1.6 & 1.0 & 2.8 & 3.7 & 3.8 & 1.0 & 1.5 & 2.5 & 2.3 \\
\hline Public health & 0.9 & 1.5 & 3.3 & 2.2 & 1.5 & 3.9 & 6.2 & 4.1 & 1.0 & 2.3 & 4.2 & 2.6 \\
\hline others & 1.0 & 1.5 & 2.9 & 2.1 & 1.0 & 2.3 & 5.0 & 3.4 & 1.0 & 2.0 & 3.5 & 2.7 \\
\hline \multicolumn{13}{|l|}{ Current occupation } \\
\hline self-employed & 0.9 & 1.2 & 2.5 & 1.8 & 2.4 & 4.6 & 8.3 & 5.4 & 1.1 & 2.5 & 5.0 & 3.7 \\
\hline company-employed & 1.0 & 1.9 & 3.5 & 2.4 & 1.1 & 2.5 & 5.1 & 3.4 & 1.0 & 2.3 & 4.1 & 2.8 \\
\hline student & 0.9 & 1.5 & 2.7 & 2.0 & 0 & 2.9 & 5.0 & 3.2 & 0.9 & 1.5 & 3.6 & 2.4 \\
\hline \multicolumn{13}{|l|}{ Partnership } \\
\hline single & 1.0 & 2.4 & 3.5 & 2.6 & 2.0 & 3.3 & 6.7 & 4.5 & 1.1 & 2.6 & 5.0 & 3.3 \\
\hline with partner & 0.9 & 1.5 & 2.9 & 2.0 & 1.0 & 2.6 & 4.7 & 3.2 & 1.0 & 1.5 & 3.6 & 2.5 \\
\hline
\end{tabular}

tion, minor risk behaviors such as lack of sleep and fast-food consumption might, if performed excessively, reach the same levels as smoking or drinking. It should be noted that, in addition to being in line with epidemiologic risk assessment, individual risk perception scores possibly allow for gauging deviations from group level perception scores and may thereby have diagnostic potential in terms of indicating individual-level misconceptions or information gaps regarding certain behavioral risks.

The LRS appears to have a very high split-half reliability and was not found to depend substantially on professional background, i.e., on whether the scoring was based on assessments of health-experts or on assessments of laymen. While the group-specific pairwise assessments did not change the ordinal sequence of specific risk behaviors, the scores were somewhat different: Tobacco use, obesity, alcohol consumption, and physical inactivity were perceived to be about 15 percent more risky when assessed by health experts as compared to laymen.

Obviously, the risk values cannot (and are not intended to) substitute for clinical and epidemiological risk quantifications. However, as the ranking of behavioral risk factors is consistent with epidemiologic risk assessment, the scale appears to be useful to identify high- risk groups and clusters of risk behaviors. As the LRS estimates individual lifestyle risks without requiring clinical measurements or detailed interviews, it might be useful in epidemiologic as well as in prevention studies, where fine-grained individual-level assessments of behavioral risk factors might be impractical.

An essential benefit of the LRS is its ability to rank health risks of different behavioral domains on a common scale. Because obesity is a result of lifestyle and not a risk behavior itself, and since the association between lack of sleep and diseases is inconsistent [34-37], the scale was, in an additional exploratory analysis, adjusted by excluding these dimensions. The scale for the remaining behavioral risk factors did not differ from the original scale using all available assessments. From this it might be concluded that other behavioral risk factors could be added to the scale in the future.

In addition to the aspect of making highly different behavioral risks comparable, the LRS allows for comparing different populations as well as different subgroups. This opens a wide field of possible applications, for example targeting groups for the specification or evaluation of behavioral intervention programs. Although information on behavioral risks can be and has often been given in an objective way by providing epidemiologic findings, the LRS does so at a different level: It 
Table 5. Risk perception scores of the sample.

\begin{tabular}{|c|c|c|c|c|c|c|c|c|c|c|c|c|}
\hline \multirow[b]{2}{*}{ Variables } & \multicolumn{4}{|c|}{ Women (N=202) } & \multicolumn{4}{|c|}{ Men $(\mathrm{N}=116)$} & \multicolumn{4}{|c|}{ Total $(\mathrm{N}=320)$} \\
\hline & $\begin{array}{c}25 \text { th } \\
\text { percentile }\end{array}$ & Median & $\begin{array}{c}\text { 75th } \\
\text { percentile }\end{array}$ & Mean & $\begin{array}{c}25 \text { th } \\
\text { percentile }\end{array}$ & Median & $\begin{array}{c}75 \text { th } \\
\text { percentile }\end{array}$ & Mean & $\begin{array}{c}25 \text { th } \\
\text { percentile }\end{array}$ & Median & $\begin{array}{c}\text { 75th } \\
\text { percentile }\end{array}$ & Mear \\
\hline total & 2.1 & 4.1 & 6.6 & 4.8 & 1.8 & 3.7 & 7.7 & 5.2 & 2.0 & 4.0 & 7.1 & 4.9 \\
\hline \multicolumn{13}{|l|}{ Age years } \\
\hline $20-29$ & 2.8 & 4.7 & 7.1 & 5.6 & 2.8 & 4.6 & 8.0 & 6.4 & 2.8 & 4.6 & 7.7 & 6.0 \\
\hline $30-39$ & 2.0 & 3.4 & 6.0 & 4.2 & 0.6 & 4.2 & 9.5 & 5.7 & 1.8 & 3.5 & 6.7 & 4.6 \\
\hline $40-49$ & 0.9 & 3.2 & 8.0 & 4.6 & 1.4 & 3.2 & 4.3 & 3.4 & 1.1 & 3.2 & 6.3 & 4.1 \\
\hline $50-59$ & 2.1 & 3.2 & 9.4 & 6.2 & 1.7 & 2.2 & 2.4 & 2.1 & 2.1 & 3.8 & 7.9 & 5.0 \\
\hline $60+$ & 7.6 & 5.7 & 7.6 & 6.2 & 0 & 1.4 & 2.7 & 1.4 & 0 & 2.7 & 7.6 & 3.4 \\
\hline no answer & 1.9 & 7.6 & 5.8 & 4.3 & 0.9 & 2.4 & 7.6 & 4.2 & 1.0 & 3.9 & 6.9 & 4.2 \\
\hline \multicolumn{13}{|l|}{ Professional training } \\
\hline Medicine & 1.8 & 3.3 & 6.2 & 4.0 & 1.0 & 3.1 & 6.9 & 3.7 & 1.7 & 3.2 & 6.4 & 3.9 \\
\hline Psychology & 3.6 & 5.1 & 8.3 & 5.9 & 2.1 & 5.3 & 9.6 & 5.8 & 3.6 & 5.2 & 8.3 & 6.3 \\
\hline Sociology/Pedagogy & 2.1 & 3.5 & 6.1 & 3.8 & 4.5 & 7.9 & 9.8 & 9.3 & 2.8 & 4.5 & 7.1 & 5.5 \\
\hline Public health & 1.2 & 3.9 & 5.4 & 4.5 & 0.4 & 2.2 & 7.1 & 3.7 & 0.9 & 3.9 & 5.8 & 4.4 \\
\hline other & 2.5 & 4.4 & 7.6 & 5.3 & 2.3 & 3.6 & 7.7 & 5.7 & 2.4 & 4.2 & 7.6 & 5.5 \\
\hline \multicolumn{13}{|l|}{ Current occupation } \\
\hline self-employed & 3.6 & 5.2 & 8.7 & 6.1 & 2.8 & 6.0 & 8.6 & 7.0 & 3.1 & 5.2 & 8.6 & 6.6 \\
\hline company-employed & 1.9 & 3.8 & 6.3 & 4.7 & 1.7 & 3.6 & 7.4 & 5.1 & 1.9 & 3.7 & 6.6 & 4.9 \\
\hline student & 1.9 & 4.6 & 6.9 & 4.6 & 2.1 & 3.6 & 7.7 & 4.5 & 2.1 & 4.4 & 6.9 & 4.6 \\
\hline \multicolumn{13}{|l|}{ Partnership } \\
\hline single & 2.0 & 4.2 & 7.1 & 4.7 & 2.4 & 3.9 & 7.7 & 5.3 & 2.1 & 4.2 & 7.6 & 4.9 \\
\hline with partner & 2.5 & 4.0 & 6.3 & 4.8 & 1.7 & 3.6 & 7.6 & 5.2 & 1.9 & 3.9 & 6.6 & 4.9 \\
\hline \multicolumn{13}{|l|}{ Weight } \\
\hline underweight & 1.8 & 6.9 & 7.2 & 5.1 & 4.6 & 4.6 & 4.6 & 4.6 & 1.8 & 5.8 & 7.2 & 5.1 \\
\hline normal weight & 2.5 & 4.1 & 6.3 & 4.7 & 2.0 & 3.5 & 7.4 & 4 & 2.1 & 3.9 & 6.5 & 4.8 \\
\hline overweight & 1.9 & 4.2 & 7.6 & 5.4 & 1.0 & 4.2 & 7.7 & 5.7 & 1.6 & 4.2 & 7.7 & 5.6 \\
\hline adiposity & - & - & - & - & 3.9 & 5.8 & 9.5 & 7.2 & 3.9 & 5.8 & 9.5 & 7.2 \\
\hline
\end{tabular}

Fast Food per week

\begin{tabular}{|c|c|c|c|c|c|c|c|c|c|c|c|c|}
\hline$<1$ & 2.0 & 4.1 & 6.6 & 4.8 & 2.2 & 4.1 & 8.3 & 5.8 & 2.0 & 4.1 & 7.3 & 51 \\
\hline up to once & 2.7 & 3.9 & 6.3 & 4.7 & 1.4 & 2.8 & 5.8 & 4.7 & 2.1 & 3.7 & 6.1 & 4.7 \\
\hline up to twice & 1.0 & 4.2 & 7.1 & 4.0 & 0.0 & 0.5 & 1.8 & 0.8 & 0.2 & 1.9 & 5.6 & 2.9 \\
\hline up to three times & 1.2 & 4.6 & 8.3 & 4.7 & 2.5 & 5.5 & 8.5 & 5.5 & 2.5 & 4.6 & 8.5 & 5.1 \\
\hline$>$ three times & - & - & - & - & 1.6 & 5.1 & 7.9 & 4.8 & 2.1 & 7.4 & 7.7 & 5.1 \\
\hline
\end{tabular}

Cigarettes per day

\begin{tabular}{|c|c|c|c|c|c|c|c|c|c|c|c|c|}
\hline \\
\hline Non-smoker & 2.1 & 4.2 & 6.6 & 4.8 & 1.6 & 3.2 & 7.4 & 4.6 & 1.9 & 3.9 & 6.9 & 4.7 \\
\hline Up to 5 & 2.1 & 3.9 & 4.6 & 3.6 & 3.5 & 5.9 & 8.6 & 7.2 & 2.5 & 4.6 & 8.0 & 5.6 \\
\hline Up to 10 & 0 & 8.0 & 15.9 & 8.0 & 3.7 & 7.4 & 8.5 & 6.1 & 0 & 7.4 & 9.5 & 6.7 \\
\hline Up to 15 & 1.4 & 3.1 & 6.3 & 3.9 & 3.5 & 9.0 & 11.0 & 9.9 & 2.8 & 4.0 & 10.1 & 7.7 \\
\hline$>15$ & 2.8 & 4.4 & 8.0 & 6.0 & 2.1 & 2.1 & 2.1 & 2.1 & 2.1 & 3.9 & 4.8 & 4.9 \\
\hline \multicolumn{13}{|l|}{ Alcohol per day } \\
\hline$<1$ drink & 2.1 & 4.2 & 6.7 & 4.8 & 1.8 & 4.0 & 7.7 & 5.4 & 2.1 & 4.1 & 7.3 & 5.0 \\
\hline Up to 1 drink & 1.9 & 3.8 & 5.7 & 4.3 & 2.1 & 3.2 & 6.0 & 4.6 & 1.9 & 3.7 & 6.0 & 4.4 \\
\hline Up to 2 drinks & 2.8 & 2.8 & 9.4 & 5.6 & 1.6 & 3.6 & 8.6 & 6.1 & 1.9 & 3.5 & 7.3 & 6.0 \\
\hline Up to 3 drinks & - & - & - & - & 0 & 0 & 7.5 & 2.5 & 6.0 & 0 & 6.0 & 2.5 \\
\hline
\end{tabular}

Physical activity per day

\begin{tabular}{|c|c|c|c|c|c|c|c|c|c|c|c|}
\hline$>30$ minutes & 2.1 & 4.2 & 6.4 & 4.8 & 2.3 & 4.1 & 7.9 & 5.8 & 2.2 & 4.1 & 7.1 \\
\hline up to 30 minutes & 2.7 & 4.1 & 6.3 & 4.9 & 0.9 & 3.2 & 7.4 & 3.8 & 1.4 & 3.7 & 6.5 \\
\hline up to 20 minutes & 1.2 & 4.0 & 5.7 & 4.1 & 0.8 & 2.6 & 7.5 & 4.4 & 0.9 & 3.1 & 6.1 \\
\hline up to 10 minutes & 2.6 & 3.8 & 9.3 & 5.8 & 2.6 & 4.8 & 10.2 & 7.6 & 2.8 & 4.0 & 10.2 \\
\hline physical activity & 2.1 & 7.8 & 8.1 & 6.1 & - & - & - & - & 2.1 & 7.8 & 8.1 \\
\hline
\end{tabular}

Days with sleep under 6h per week

\begin{tabular}{|c|c|c|c|c|c|c|c|c|c|c|c|c|}
\hline$<1$ & 2.0 & 4.4 & 6.9 & 5.1 & 1.7 & 2.8 & 8.6 & 5.5 & 1.8 & 4.2 & 7.6 & 5.2 \\
\hline up to 1 & 1.8 & 3.5 & 6.7 & 4.2 & 1.2 & 3.9 & 7.6 & 5.1 & 2.0 & 3.7 & 6.8 & 4.6 \\
\hline up to 2 & 2.1 & 4.1 & 6.2 & 5.0 & 2.4 & 3.6 & 7.1 & 4.4 & 2.2 & 4.1 & 6.4 & 4.7 \\
\hline up to 3 & 0.0 & 2.8 & 4.2 & 2.4 & 0.4 & 3.8 & 6.6 & 4.2 & 0.0 & 2.8 & 5.1 & 3.5 \\
\hline$>3$ & 2.4 & 4.6 & 7.3 & 5.1 & 3.4 & 12.2 & 14.8 & 11.0 & 2.7 & 4.9 & 9.1 & 5.9 \\
\hline
\end{tabular}


allows people to obtain, based on fine-grained levels of assessment, feedback on their risk perception and/or health-related behavior as compared to others, thus possibly supporting them in adjusting their views and lifestyles.

By applying the LRS to the actual behaviors of the study population, some interesting findings were obtained, although the present sample had a rather low average risk score and reported rather healthy lifestyles. The findings that lifestyles were healthier in female than in male participants, that participants living with a partner led healthier lifestyles than singles, and that younger participants engaged more often in risky lifestyles than older ones correspond well with findings reported in the literature [38-45]. Although men perceived risks more accurately, their lifestyles were more risky than those of females. Also, professionals with medical training did not show less risky behaviors than others, even though they perceived health risks as more serious. This corresponds to the well-known fact that being aware of risks does not automatically lead to their avoidance [46].

It is clear that independent validation of the LRS should be undertaken prior to applying it without reservation in research or individual-level diagnostic or interventional settings. Out-of-sample replication studies and possibly recalibration of the proposed scoring should be undertaken. Other than the present sampling and measurement procedures might provide important insights regarding the generalizability of the scale and the reported findings. The response rate of 67 percent was reasonably high and selection bias seems to be unlikely. While there appears to be no prima facie reason to assume that the sampling procedure might have biased the results, this possibility cannot be fully excluded. Replication studies might therefore attempt to draw population-representative random samples of study participants. Also, epidemiological analyses of the predictive value of the LRS should be undertaken, either based on existing data (where available) or on data of future case-control or (preferably) prospective cohort studies. By addressing different disease-specific endpoints and settings, a fine grained purpose-specific assessment of the instrument might eventually become available.

In summary, it was possible to quantify multidimensional health-behaviors and risk perceptions concisely with a unidimensional risk scale. The LRS, although preliminary at present, can be useful in epidemiologic research as well as in developing and evaluating interventions, and possibly as a tool for risk communication in prevention contexts. There is ample evidence that for most diseases, effective strategies for risk communication need to focus on health-related behaviors $[2,4]$. Scoring multidimensional health-related behavioral risks on a single dimension of subjective risk appears now feasible, but additional work is required to further validate and calibrate the instrument.

\section{ACKNOWLEDGEMENTS}

There was no funding for this project.

\section{REFERENCES}

[1] Weisburger, J. (1998) Worldwide prevention of cancer and other chronic diseases based on knowledge of mechanisms. Mutatution Research, 402, 331-337. doi:/10.1016/S0027-5107(97)00313-8

[2] Blanchard, C.G., Labrecque, M.S., Ruckdeschel, J.C. and Blanchard, E.B. (1988) Information and decision-making preferences of hospitalized adult cancer patients. Social Science \& Medicine, 27, 1139-1145. doi:/10.1016/0277-9536(88)90343-7

[3] Barbor, T., Sciamanna, C. and Pronk, N. (2004) Assessing multiple risk behaviors in primary care. Screening issues and related concepts. American Journal of Preventive Medicine, 27, 42-53.

[4] Rimm, E. and Stampfer, M. (2004) Diet, lifestyle, and longevity-The next steps? Journal of the American Medical Association, 292, 1490-1492.

doi:/10.1001/jama.292.12.1490

[5] Battegay, E., Gasche, A., Zimmerli, L., Martina, B., Gyr, N. and Keller, U. (1997) Risk factors control and perceptions of risk factors in patients with coronary heart disease. Blood Press Supplies, 1, 17-22.

[6] Cohn, L., Schydlower, M., Foley, J. and Copeland, R. (1995) Adolescents' misinterpretation of health risk probability expressions. Pediatrics, 95, 713-716.

[7] Tsubono, Y., Koizumi, Y., Nakaya, N., Fujita, K., Takahashi, H., Hozawa, A., Suzuki, Y., Kuriyama, S., Tsuji, I., Fukao, A. and Hisamichi, S. (2004) Health practices and mortality in Japan: combined effects of smoking, drinking, walking and body mass index in the Miyagi Cohort Journal of Epidemiology, 14, S39-45. doi:/10.2188/jea.14.S39

[8] Mao, Y., Pan, S., Wen, S.W. and Johnson, K.C. (2003) Physical inactivity, energy intake, obesity and the risk of rectal cancer in Canada. International Journal of Cancer, 105, 831-837. doi:/10.1002/ijc. 11159

[9] Kjaer, M. (2000) Physical inactivity is an underestimated risk factor for development of morbidity and mortality. Scandinavian Journal of Medicine and Science in Sports, 10, 247-248.

[10] Heidrich, J., Wellmann, J., Hense, H.W., Siebert, E., Liese, A.D., Lowel, H. and Keil, U. (2003) Classical risk factors for myocardial infarction and total mortality in the community-13-year follow-up of the MONICA Augsburg cohort study. Z Kardiol, 92, 445-454.

[11] Haveman-Nies, A., De Groot, L., Burema, J., Cruz, J., Osler, M. and van Staveren, W. (2002) Dietary quality and lifestyle factors in relation to 10 -year mortality in older Europeans. The SENECA study. American Journal of Epidemiology, 156, 962-968. doi:/10.1093/aje/kwf144

[12] Emberson, J., Shaper, A., Wannemethee, S., Morris, R. 
and Whincup, P. (2005) Alcohol Intake in middle age and risk of cardiovascular disease and mortality: Accounting for intake variation over time. American Journal of Epidemiology, 161, 856-863. doi:/10.1093/aje/kwil11

[13] Bercault, N., Boulain, T., Kuteifan, K., Wolf, M., Runge, I. and Fleury, J.C. (2004) Obesity-related excess mortality rate in an adult intensive care unit: A risk-adjusted matched cohort study. Critical Care Medicine, 32, 9981003. doi:/10.1097/01.CCM.0000119422.93413.08

[14] Belloc, N. (1973) Relationship of health practices and mortality. Preventive Medicine, 2, 67-81. doi:/10.1016/0091-7435(73)90009-1

[15] Andersen, L.B. (2004) Relative risk of mortality in the physically inactive is underestimated because of real changes in exposure level during follow-up. American Journal of Epidemiology, 160, 189-195. doi:/10.1093/aje/kwh195

[16] World Health Organization. (1999) Healthy living. What is a healthy lifestyle? Copenhagen, Denmark: World Health Organization Regional Office for Europe. World Wide Web URL:

http://www.euro.who.int/document/e66134.pdf

[17] Meng, L., Maskarinec, G., Lee, J. and Kolonel, L. (1999) Lifestyle factors and chronic diseases: application of a composite risk index. Preventive Medicine, 29, 296-304. doi:/10.1006/pmed.1999.0538

[18] Kim, S., Popkin, B., Siega-Riz, A., Haines, P. and Arab, L. (2004) A cross-national comparison of lifestyle between China and the United States, using a comprehendsive cross-national measurement tool of the healthfulness of lifestyles: The Lifestyle Index. Preventive Medicine, 38, 160-171. doi:/10.1016/j.ypmed.2004.02.003

[19] D'Agostino, B., Grundy, S., Sullivan, L. and Wilson, P. (2001) Validation of the Framingham Coronary Heart Disease Prediction Scores. Results of a Multiple Ethnic Groups Investigation. Journal of the American Medical Association, 286, 180-187. doi:/10.1001/jama.286.2.180

[20] Aktas, M., Ozduran, V., Pothier, C., Lang, R. and Lauer, M. (2004) Global risk scores and exercise testing for predicting all-cause mortality in a preventive medicine program. Journal of the American Medical Association, 292, 1462-1468. doi:/10.1001/jama.292.12.1462

[21] Agresti, A. (1996) Chapter 9.6. Bradley-Terry model for paired preferences, Eds., An introduction to categorial data analysis, John Wiley \& Sons, Inc., New York, 246279.

[22] Klein, M. (2002) Die Conjoint-Analyse. Eine Einführung in das Verfahren mit einem Ausblick auf mögliche sozialwissenschaftliche Anwendungen. ZA-Information 50, 7-45.

[23] Gediga, G. (1998) Kapitel 6. Wahlmodelle für PräferenzDatenEds., Skalierung. Eine Einführung in die Me- thodik zur Entwicklung von Testund Meßinstrumenten in den Verhaltenswissenschaften, Lit Verlag, Münster, 90106.

[24] SAS Institute. Samples: Bradley. SAS Institute, 2000. World Wide Web URL: http://ftp.sas.com/techsup/download/stat/bradley.html

[25] Cronbach, L.J. (1951) Coefficient alpha and the internal structure of tests. Psychometrika, 16, 297-334.

[26] Bland, M.J. and Altman, D.G. (1997) Cronbach's alpha. British Medical Journal, 314, 572.
[27] Mokdad, A., Marks, J., Stroup, D. and Gerbering, J. (2004) Actual causes of death in the United States, 2000. Journal of the American Medical Association, 291, 12381245. doi:/10.1001/jama.291.10.1238

[28] Keil, U. and Kuulasmaa, K. (1989) WHO MONICA Project: risk factors. American Journal of Epidemiology, 18, S46-S55.

[29] Jaatun, H.J., Sutradhar, S.C. and Dickstein, K. (2004) Comparison of mortality rates after acute myocardial infarction in smokers versus nonsmokers. American Journal of Cardiology, 94, 632-636, A9.

[30] Haustein, K. (2003) Smoking and body weight - a main topic. Deutsche Medizinische Wochenschrift, 128, 2085 2090.doi:/10.1055/s-2003-42705

[31] Wellmann, J., Heidrich, J., Berger, K., Doring, A., Heuschmann, P.U. and Keil, U. (2004) Changes in alcohol intake and risk of coronary heart disease and all-cause mortality in the MONICA/KORA-Augsburg cohort 19871997. European Journal of Cardiovascular Prevention \& Rehabilitation, 11, 48-55. doi:/10.1097/01.hjr.0000118174.70522.20

[32] San-Jose, B. (2003) Alcohol consumption and mortality: Comparison between countries and meta-analyses. European Journal of Epidemiology, 18, 603-605. doi:/10.1023/A:1024985601188

[33] de Vegt, F., Dekker, J.M., Groeneveld, W.J., Nijpels, G., Stehouwer, C.D., Bouter, L.M. and Heine, R. J. (2002) Moderate alcohol consumption is associated with lower risk for incident diabetes and mortality: the Hoorn Study. Diabetes Research and Clinical Practice, 57, 53-60. doi:/10.1016/S0168-8227(02)00013-X

[34] Youngstedt, S.D. and Kripke, D.F. (2004) Long sleep and mortality: have we been chasing the wrong tail? Sleep Medicine Reviews, 8, 175-176. doi:/10.1016/j.smrv.2004.03.001

[35] Tamakoshi, A. and Ohno, Y. (2004) Self-reported sleep duration as a predictor of all-cause mortality: Results from the JACC study, Japan. Sleep, 27, 51-54.

[36] Kripke, D.F. (2003) Sleep and mortality. Psychosomatic Medicine, 65, 74. doi:/10.1097/01.PSY.0000039752.23250.69

[37] Heslop, P., Smith, G.D., Metcalfe, C., Macleod, J. and Hart, C. (2002) Sleep duration and mortality: The effect of short or long sleep duration on cardiovascular and all-cause mortality in working men and women. Sleep Medicine, 3, 305-314. doi:/10.1016/S1389-9457(02)00016-3

[38] Becker, C. and Arnold, W. (2004) Health Promoting behaviors of older Americans versus young and middle aged adults. Educational Gerontology, 30, 835-844. doi:/10.1080/03601270490507277

[39] Burger, M. and Mensink, G. (2003) Bundes-gesund-heitssurvey: Alkohol. konsumverhalten in deutschland. Beiträge zur gesundheitsberichterstattung des bundes, Robert Koch-Institut, 1-16.

[40] Fransson, E., Alfredsson, L., de Faire, U., Knutsson, A. and Westerholm, P. (2003) Leisure time, occupational and household physical activity, and risk factors for cardiovascular disease in working men and women: The WOLF study. Scandinavian Journal of Public Health, 31, 324-333. doi:/10.1080/14034940210165055

[41] Freidl, W., Stronegger, W. and Neuhold, C. (2003) Le- 
bensstile in Wien. Stadt Wien (Hrsg.), 1-320.

[42] Knopf, H., Ellert, U. and Melchert, H. (1999) Sozialschicht und Gesundheit. Gesundheitswesen, 61, S169-S177.

[43] Mensink, G. (2003) Beiträge zur Gesundheitsberichterstattung des Bundes. Bundes-Gesundheitssurvey: Körperliche Aktivität. Aktive Freizeitgestaltung in Deutschland. Robert Koch-Institut, 1-12.

[44] Sánchez-Villegas, A., Delgado-Rodríguez, M., MartínezGonzález, M., de Irala-Estévez, J. et al. (2003) Gender, age, socio-demographic and lifestyle factors associated with major dietary patterns in the Spanish project SUN (Seguimiento Universidad de Navarra). European Journal of Clinical Nutrition, 57, 285-292. doi:/10.1038/sj.ejen.1601528

[45] Umberson, D. (1987) Family status and health behaviors: social control as a dimension of social integration. Jour nal of Health and Social Behavior, 28, 306-319. doi:/10.2307/2136848

[46] LaPiere, R. (1934) Attitudes versus actions. Social Forces, 13, 230-237. doi:/10.2307/2570339 